\title{
Oxytocin: The Neurohormone
}

\section{Tabassum Zafar* and Vinoy K Shrivastava \\ Department of Bioscience, Barkatullah University, India}

*Corresponding author: Tabassum Zafar, Department of Bioscience, Barkatullah

University, Bhopal, India 462026, Email: tztabassumzafar@gmail.com

\section{Mini Review \\ Volume 4 Issue 1}

Received Date: February 07, 2019

Published Date: February 23, 2019

DOI: $10.23880 /$ act-16000148

\section{Abstract}

Oxytocin is a peptide hormone, which serves important functions in body including labor management and lactation. Indiction of milk ejection and easy delivery there are many other aspects of in vivo oxytocin functions. Neurotransmission within the body is one of the important vital functions of oxytocin, which validates involvement of oxytocin in emotional, neuronal and behaviour balance of body. Present mini review discusses important facts and phenomenon's associated with oxytocin.

Keywords: Oxytocin; Love Hormone; Neurohormone

\section{Introduction}

Oxytocin is a neuropeptide endocrine secretion produced by the paraventricular nucleus of the hypothalamus and released by the posterior pituitary. In 1906, Sir Henry Dale coined the term 'Oxytocin' for the chemical released from posterior pituitary to promotes 'swift birth' by affecting the uterine contractions in pregnant cats. After 47 years of this, Vincent du Vigneaud had received Nobel Prize in 1955 for sequencing and synthesizing the oxytocin [1].

Oxytocin is an evolutionarily conserved neurohypophysial hormone, which is made up of nine amino acids. It is almost similar to the neighbouring hormone vasopressin except the presence of leucine as third amino acid, while vasopressin contains an arginine at the same [2]. Oxytocin has class I G protein-coupled receptor with a requirement of $\mathrm{Mg} 2+$ and cholesterol. In humans many peripheral organs such as kidney, heart, thymus, pancreas, adipocytes, uterus, and brain differentially express the oxytocin receptors [3]. The oxytocin receptor density varies in between males and females. Apart from humans oxytocin receptors are also distributed in pigs, rats, sheep, bovine, mice, and rhesus monkey [4].
Oxytocin is mainly responsible for inducing sufficient uterine movement during the child birth and it also induces lactation in postpartum phase. Oxytocin has evident scientific association with various biological and cognitive process including empathy, trust, sexual activity, and relationship-building, social bonding, sexual reproduction and most importantly childbirth and breast feeding [5].

These amazing qualities of this neurohormone makes it an interesting candidate for treatment of a number of clinical conditions such as artificial assistance to childbirth, depression, anxiety, autistic spectrum disorder intestinal problems, irritable bowel syndrome etc. [6].

In aid to reproductive functions of oxytocin, it also plays various major roles in expression of physical and psychological characters. Oxytocin is many times synonyms with "love hormone," and "cuddle hormone" because it is secreted during romance, love making, hugging and orgasm [7]. Oxytocin is an active influencer of emotions, when oxytocin releases in the blood stream it creates a feeling of trust, affection and social attachment. It is assumed that the first stage of romantic attachment is under the influence of persistently high levels of oxytocin, 
which remain high for about to 6 months $[8,9]$. High levels of this love hormone act to facilitate the sociosexual behaviour and attachment between the lovers. High level of circulating oxytocin is the one of the main culprit to create psychological romantic blues and makes the love satisfying and pleasures. Pair bondig between adults and lovers happens under the influence of dopaminergic activity within the nucleus accumbens. Nucleus accumbens of brain has a very rich in oxytocin receptor density [10-12].

So, when the next time you feel romantic butterfly in stomachs better to think about oxytocin. When the good news about arrival of a baby is reached to you, think of oxytocin. When you find someone trustworthy, think of oxytocin. When you feel like a social butterfly, think of oxytocin. When you are about to choose a partner, think of oxytocin. When you express gratitude to your mother for feeding you during the infancy, think of oxytocin, which worth more than a hormone and versatile more than a neurotransmitter.

\section{References}

1. Du Vigneaud V (1956) Trail of sulfur research: from insulin to oxytocin. Science 123(3205): 967-974.

2. Farina Lipari E, Valentino B, Lipari D (1995) Immunohistochemical research on oxytocin in the hypothalamic accessory nuclei. Ital J Anat Embryol 100(4): 189-193.

3. Gimpl G, Fahrenholz F (2001) The oxytocin receptor system: structure, function, and regulation. Physiol Rev 81(2): 629-683.
4. Gimpl G, Reitz J, Brauer S, Trossen C (2008) Oxytocin receptors: ligand binding, signalling and cholesterol dependence. Prog Brain Res 170: 193-204.

5. Lee HJ, Macbeth AH, Pagani J, Young WS. (2009)Oxytocin: the great facilitator of life. Prog Neurobiol 88(2): 127-151.

6. Mitre M (2018) Oxytocin Modulation of Neural Circuits. Curr Top Behav Neurosci 35: 31-53.

7. Argiolas A, Gessa GL (1991) Central functions of oxytocin. Neurosci Behav Rev 15(2): 217-231.

8. Magon N, Kalra S (2011) The orgasmic history of oxytocin: Love, lust, and labor. Indian J Endocrinol Metab 15(3): S156-61.

9. Algoe SB, Kurtz LE, Grewen K (2017) Oxytocin and social bonds: the role of oxytocin in perceptions of romantic partners bonding behaviour. Psychol Sci 28(12): 1763-1772.

10. Aleksidze NG (2018) The Quantitative Distribution of the Hormones of Love and Neurotransmitters at Psycho Emotional Stresses. Psychol Psychology Res Int J 3(5): 1-8.

11. Liu Y, Wang ZX (2003) Nucleus accumbens oxytocin and dopamine interact to regulate pair bond formation in female prairie voles. Neurosci 121(3): 537-544.

12. Wudarczyk OA., Earp BD, Guastella A, Savulescu J (2013) Could intranasal oxytocin be used to enhance relationships? Research imperatives, clinical policy, and ethical considerations. Curr Opin Psychiatry 26(5): 474-484. 